\title{
Corrosion Performance of Aluminum-containing Zinc Coatings
}

\author{
Nai-Yong TANG and Yihui LIU \\ Product Technology Centre, Teck Metals Ltd., 2380 Speakman Drive, Mississauga, Ontario, Canada. \\ E-mail: naiyong.tang@teck.com, daniel.liu@teck.com
}

(Received on March 9, 2009; accepted on November 25, 2009)

\begin{abstract}
Corrosion performance of zinc coatings containing aluminum in excess of $5 \%$ was assessed in modified salt-spray tests. X-ray diffraction studies indicated that the corrosion products consisted mainly of simonkolleite $\mathrm{Zn}_{5}(\mathrm{OH})_{8} \mathrm{Cl}_{2} \cdot \mathrm{H}_{2} \mathrm{O}$, hydrozincite $\mathrm{Zn}_{5}(\mathrm{OH})_{6}\left(\mathrm{CO}_{3}\right)_{2}$, and zinc aluminum carbonate hydroxide hydrate $\mathrm{Zn}_{6} \mathrm{Al}_{2}(\mathrm{OH})_{16} \mathrm{CO}_{3} \cdot 4\left(\mathrm{H}_{2} \mathrm{O}\right)$. The content of $\mathrm{Zn}_{6} \mathrm{Al}_{2}(\mathrm{OH})_{16} \mathrm{CO}_{3} \cdot 4\left(\mathrm{H}_{2} \mathrm{O}\right)$ in the corrosion product increased as the aluminum content in the coatings increased. SEM-EDX analyses revealed that the microstructural features formed by the primary aluminum-rich $\alpha$-phase frequently corroded first and at a faster pace than the zinc-rich $\beta$-phase in these coatings. The volume fraction and morphology of the zinc-rich $\beta$-phase existing in the coatings as degenerated eutectic are the two main factors which determine the corrosion resistance of $\mathrm{Zn}-\mathrm{Al}$ coatings under development. The corrosion resistance of coatings peaked at about $12 \% \mathrm{Al}$ in this study.
\end{abstract}

KEY WORDS: corrosion; hot-dip galvanizing; microstructure; coating; zinc; aluminum.

\section{Introduction}

A development program investigating various $\mathrm{Zn}-\mathrm{Al}$ alloys for batch galvanizing was initiated several years ago at the University of Cincinnati, Cincinnati, Ohio, USA in collaboration with the Weert Groep, a galvanizing company based in the Netherlands. ${ }^{1)}$ In 2003, at the request of Prof. Wim van Ooij, Teck Metals Ltd. became a member of the development team and has contributed significantly to the development program ever since. ${ }^{2)}$ The original objective of the development program was to improve the corrosion resistance of hot-dipped galvanized coatings, thereby reducing zinc run-off from galvanized structural units such as guard rails, light poles, transmission towers, railings and fasteners. Work at the University of Cincinnati initially focused on an alloy composition of $\mathrm{Zn}-23 \% \mathrm{Al}$. However, subsequent literature surveys and in-house corrosion tests carried out at Teck's Product Technology Centre (PTC) suggested that the $\mathrm{Zn}-23 \% \mathrm{Al}$ alloy was not an optimal composition for either corrosion resistance or processability in hot-dip galvanizing, especially with respect to bath temperature requirements and coatability. In 2008, systematic corrosion tests were carried out at PTC, and the outcome of these tests suggested that the corrosion resistance of coatings could be further improved with a reduction in the aluminum content in the coating alloy. In light of these findings, work has since been carried out at PTC to develop alloys with an improved corrosion resistance and better processability in hot-dip galvanizing. A thorough understanding of the corrosion mechanisms of $\mathrm{Zn}-\mathrm{Al}$ coatings is critical to the success of the alloy development program at Teck. As a result, a detailed study of the corrosion of $\mathrm{Zn}-\mathrm{Al}$ coatings was carried out recently, and the results are reported here.

\section{Experimental}

Coating samples were produced in PTC's laboratory. Hot-rolled low-carbon steel coupons, $150 \mathrm{~mm} \times 100 \mathrm{~mm} \times 3$ $\mathrm{mm}$, were degreased in a caustic solution for $1 \mathrm{~h}$, rinsed with tap water and pickled in an $18 \%$ hydrochloric acid solution for $40 \mathrm{~min}$, and rinsed with tap water again. The coupons were then immersed in a proprietary flux bath for $45 \mathrm{~s}$. The fluxed samples were dried for $4 \mathrm{~min}$ in a conventional oven set at $150^{\circ} \mathrm{C}$; the temperature of the samples, however, was only about $100^{\circ} \mathrm{C}$. The samples were then hot-dip galvanized individually in baths containing the desirable aluminum levels of $5 \%, 7 \%, 9 \%, 12 \%, 15 \%$ and $23 \%$. The bath temperature was individually adjusted to $30^{\circ} \mathrm{C}$ above the liquidus temperature of the contained alloy, and the dipping time was invariably $4 \mathrm{~min}$. The samples were withdrawn from the bath at a speed of $35 \mathrm{~mm} / \mathrm{s}$ using an automatic dipping device.

In the first test, the $15 \% \mathrm{Al}$ and $23 \% \mathrm{Al}$ coatings (hereafter referred to as $15 \mathrm{Al}$ and $23 \mathrm{Al}$ ) were compared to other commercial coatings such as galvanneal (GA), $\mathrm{Zn}-5 \% \mathrm{Al}$ containing misch metals (GF), and $\mathrm{Zn}-55 \% \mathrm{Al}-1.5 \% \mathrm{Si}$ (GL). Coupons with a hot-dip galvanized (HDG) pure zinc coating were also included as the benchmark. A modified salt-spray test ${ }^{3)}$ was used to evaluate the coatings. One bare uncoated steel coupon was tested for validation of the test.

The test is cyclic in nature, with each cycle lasting $45 \mathrm{~min}$, including a spray of salty fog $(0.01 \mathrm{M} \mathrm{NaCl}$ aqueous solution) for $15 \mathrm{~min}$ followed by a $30 \mathrm{~min}$ drying period at a temperature of $35^{\circ} \mathrm{C}$. Only one side of the test coupons, $100 \mathrm{~mm} \times 150 \mathrm{~mm}$ in size, faced the corrosive fog. The 
other side of the coupon was almost non-corroded at the end of the test. This greatly facilitated the comparison of the morphology and microstructure of the corroded and the non-corroded coatings. The mass of each coupon was measured before the test with a high-precision scale, and the mass of the corroded coupon was periodically monitored after pre-determined numbers of test cycles. After each round of weight measurement, the locations of the tested coupons were randomized using a computer program. Five galvanized coupons were prepared for each coating alloy and tested concurrently. Among them, four coupons were used in the destructive measurement of coating mass loss at the end of the four-week corrosion test while the remaining coupon was examined using X-ray Diffractometry (XRD) and Scanning Electron Microscopy (SEM) coupled with Energy Dispersive Spectrometry (EDS). To measure the mass loss, the corrosion products were removed initially with a saturated solution of glycine at room temperature, a procedure used by the French Corrosion Institute ${ }^{4}$ in a contract research project prior to this study. It was found in the first corrosion test that the glycine solution removed the corrosion products effectively only for coatings containing up to $5 \% \mathrm{Al}$. Coatings with an aluminum content higher than $15 \%$ were then pickled again in a $20 \%$ chromium trioxide water solution (i.e., chromic acid) at a temperature of 70 to $80^{\circ} \mathrm{C}$ for one minute per the ASTM G1 procedure. The ASTM procedure was used for all coatings in the second corrosion test. The X-ray diffraction patterns for the corrosion layers on the coupon were obtained using a Rigaku SA-HF3 XRD operated at $50 \mathrm{kV}$ and $40 \mathrm{~mA}$ by $\mathrm{Cu} K \alpha$ radiation.

\section{Results}

It is known that the corrosion rate of bare uncoated steel is about ten to twenty times higher than that of HDG zinc coating in atmospheric exposures. Such a ratio was reproduced in the current test, suggesting this accelerated laboratory test can quite realistically rate the corrosion performance of a coating in service.

The results of the first corrosion test are presented graphically in Figs. 1(a) and 1(b). Since coating thickness is known to affect the corrosion performance of coated coupons, the weights of various types of coatings are also superimposed in Fig. 1(b). The results shown in Fig. 1 indicate that the $15 \mathrm{Al}$ coating performed significantly better than the $23 \mathrm{Al}$ coating and also outperformed all other coatings except the GL coating.

Encouraged by the results of the first test, the $15 \mathrm{Al}$ coating was further tested against coatings containing $7 \% \mathrm{Al}$, $9 \% \mathrm{Al}$ and $12 \% \mathrm{Al}$ in an attempt to identify an optimal coating composition for the best corrosion resistance. The retest of $15 \mathrm{Al}$ coating facilitated direct comparisons between the results of two corrosion tests. The mass gain and mass loss of the coatings in the second test are shown in Fig. 2. The mass gain of $12 \mathrm{Al}$ coating was clearly the lowest among all coatings tested, as displayed in Fig. 2(a). The mass losses of $12 \mathrm{Al}$ and $15 \mathrm{Al}$ were similar and were marginally lower than other coatings, as shown in Fig. 2(b).

Metallurgical examinations of the corroded coatings indicated that the corrosion was not uniform over the entire

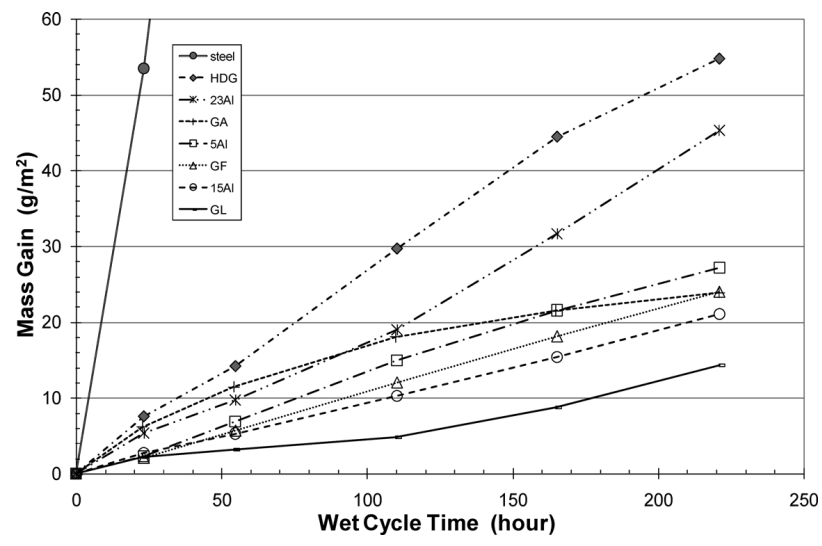

Fig. 1(a). Standardized mass gains of alloy coatings in $\mathrm{g} / \mathrm{m}^{2}$ as a function of test time in hours. The $15 \mathrm{Al}$ alloy coating outperformed all coatings, except that of the $\mathrm{Zn}-$ 55Al-1.5Si alloy, tested concurrently. Only the fog spraying time is counted in the plot.

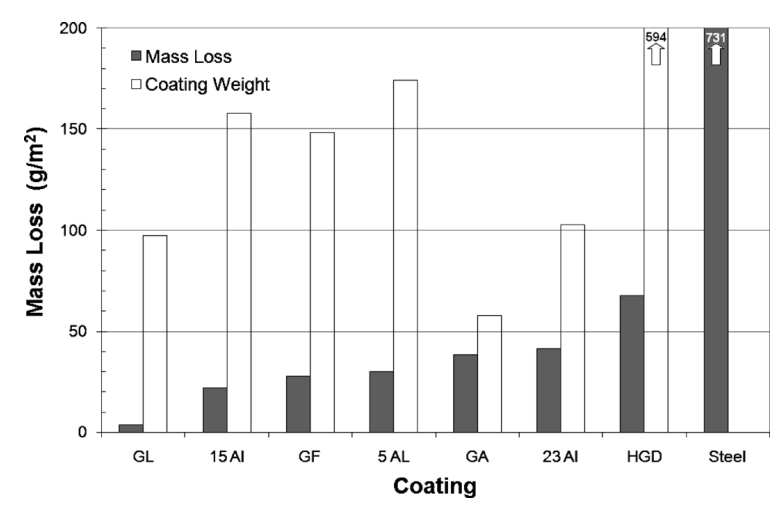

Fig. 1(b). Standardized mass losses of various alloy coatings in $\mathrm{g} / \mathrm{m}^{2}$ after the four-week test with a total fog spray time of $221 \mathrm{~h}$. The $15 \mathrm{Al}$ coating noticeably outperformed the $23 \mathrm{Al}$ coating in the test.

coating surface, presumably due to the non-uniform distribution of the salty fog. The corrosion was frequently more advanced in some locations, as shown in Fig. 3. However, following a thorough examination of all corroded coatings, the corrosion mode of these $\mathrm{Zn}-\mathrm{Al}$ coatings was found to be uniform in general, i.e., the corrosion front advanced more or less uniformly along the coating thickness although the microstructural features formed by the aluminum-rich $\alpha$-phase (fcc) frequently corroded first and slightly faster than the zinc-rich $\beta$-phase (hcp) in these coatings. The microstructures of the non-corroded and corroded $15 \mathrm{Al}$ coating are shown in Figs. 4(a) and 4(b); the corresponding microstructures for the 12Al coating are shown in Figs. 5(a) and 5(b).

The compositions of the corroded coatings were analyzed using the SEM-EDS technique. A composition map for the 15Al coating is shown in Fig. 6.

$\mathrm{X}$-ray diffraction studies of the corrosion products were carried out on coatings containing $5 \% \mathrm{Al}, 15 \% \mathrm{Al}$, and $23 \% \mathrm{Al}$. A corroded hot-dip galvanized coating containing only a trace amount of aluminum was also subjected to the $\mathrm{X}$-ray diffraction study for comparison. Analyses of the patterns indicated that the corrosion product consisted of mainly simonkolleite $\mathrm{Zn}_{5}(\mathrm{OH})_{8} \mathrm{Cl}_{2} \cdot\left(\mathrm{H}_{2} \mathrm{O}\right)$, hydrozincite $\mathrm{Zn}_{5}(\mathrm{OH})_{6}\left(\mathrm{CO}_{3}\right)_{2}$, and zinc aluminum carbonate hydroxide 


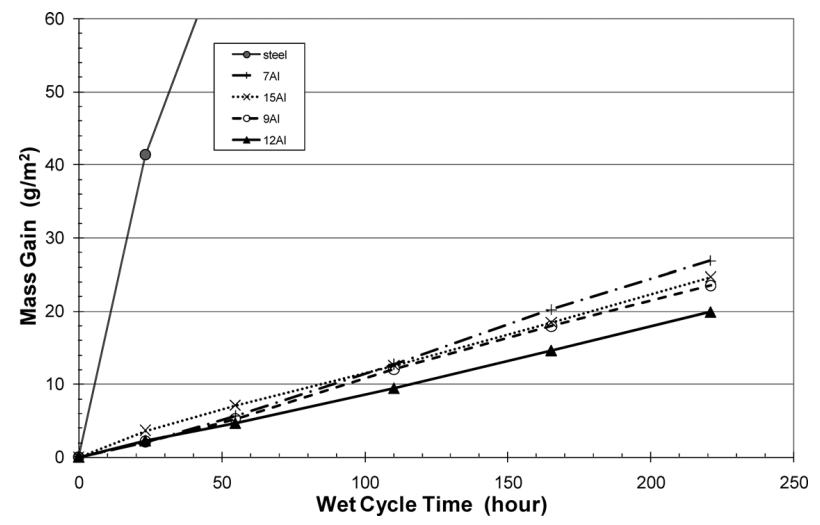

Fig. 2(a). Standardized mass gains of alloy coatings in $\mathrm{g} / \mathrm{m}^{2}$ as a function of test time in hours. Only the fog spraying time is recorded here.

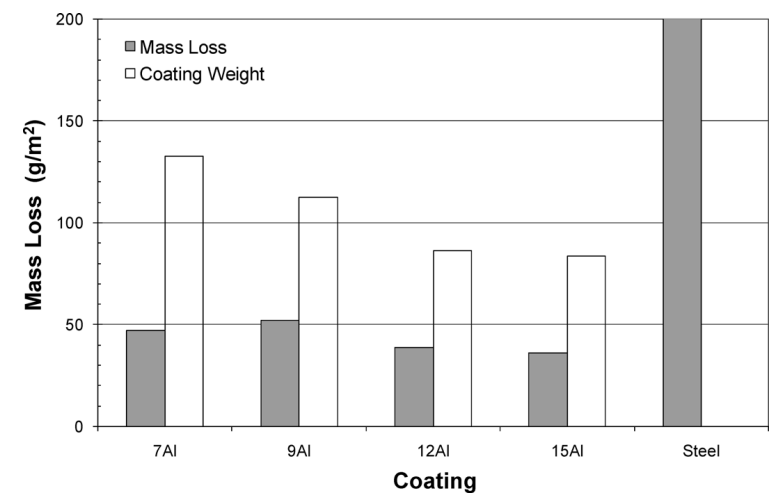

Fig. 2(b). Standardized mass losses of various alloy coatings in $\mathrm{g} / \mathrm{m}^{2}$ after the four-week test with a total fog spray time of $221 \mathrm{~h}$. The $12 \mathrm{Al}$ and $15 \mathrm{Al}$ alloys performed best in the test.
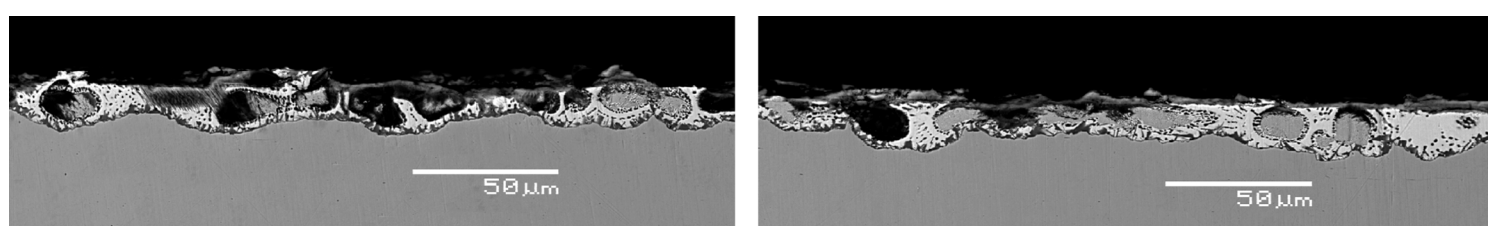

Fig. 3. Cross-sectional views of the $12 \mathrm{Al}$ coating after the corrosion test. Corrosion developed into a more advanced stage in the location shown in the left micrograph than that shown on the right. Some pockets of the primary $\alpha$ phase were totally corroded.

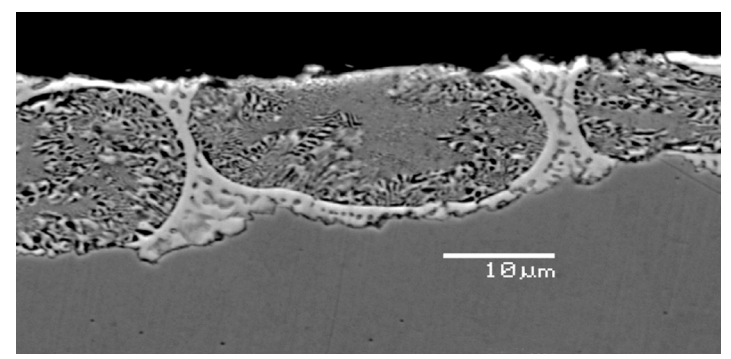

Fig. 4(a). Grain structure of the 15Al coating on the non-corroded side of the coupon. The primary $\alpha$-phase has decomposed through the eutectoid reaction.

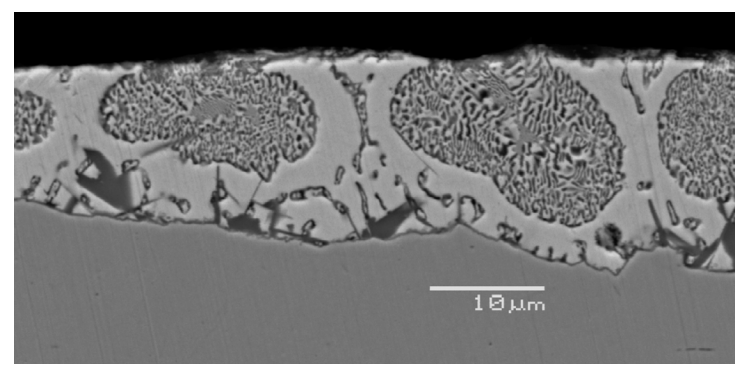

Fig. 5(a). Non-corroded grain structure of the 12Al coating.

hydrate $\mathrm{Zn}_{6} \mathrm{Al}_{2}(\mathrm{OH})_{16} \mathrm{CO}_{3} \cdot 4\left(\mathrm{H}_{2} \mathrm{O}\right)$. The X-ray patterns generated on these coatings evolved systematically. The portion of the $\mathrm{Zn}_{6} \mathrm{Al}_{2}(\mathrm{OH})_{16} \mathrm{CO}_{3} \cdot 4\left(\mathrm{H}_{2} \mathrm{O}\right)$ increased with an increase in aluminum content in the coatings. It was the dominant corrosion product on the $15 \mathrm{Al}$ and $23 \mathrm{Al}$ coatings. Note that $\mathrm{Zn}_{6} \mathrm{Al}_{2}(\mathrm{OH})_{16} \mathrm{CO}_{3} \cdot 4\left(\mathrm{H}_{2} \mathrm{O}\right)$ is isomorphic to $\mathrm{Zn}_{0.56}$ $\mathrm{Al}_{0.44}(\mathrm{OH})_{2}\left(\mathrm{CO}_{3}\right)_{0.22} \cdot x\left(\mathrm{H}_{2} \mathrm{O}\right)$. The latter, with higher aluminum content, has a slightly smaller cell size and, hence,

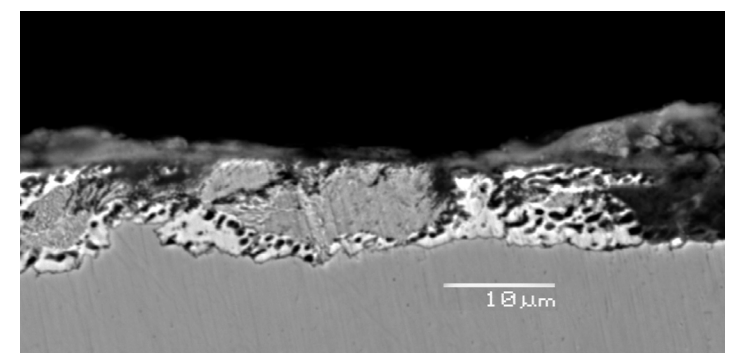

Fig. 4(b). Microstructure of the corroded $15 \mathrm{Al}$ coating. The decomposed aluminum-rich primary $\alpha$-phase corroded faster than the degenerated pure zinc $\beta$-phase.

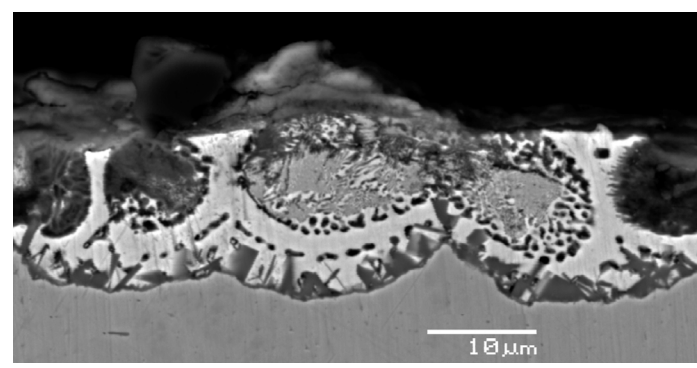

Fig. 5(b). Microstructure of the corroded 12Al coating. Zinc in degenerated eutectic is much more corrosion resistant.

slightly larger $2 \theta$ angles for corresponding peaks. It was found that the $\mathrm{Zn}_{6} \mathrm{Al}_{2}(\mathrm{OH})_{16} \mathrm{CO}_{3} \cdot 4\left(\mathrm{H}_{2} \mathrm{O}\right)$ peaks for $23 \mathrm{Al}$ shifted slightly to the right, i.e., larger $2 \theta$ angles when compared to the corresponding peaks for $15 \mathrm{Al}$. Apparently, the ample supply of aluminum from the coating favored the formation of a corrosion product with higher aluminum content. Shown in Figs. 7(a) to 7(d) are X-ray diffraction patterns generated from corroded $\mathrm{HDG}, 5 \mathrm{Al}, 12 \mathrm{Al}$ and 

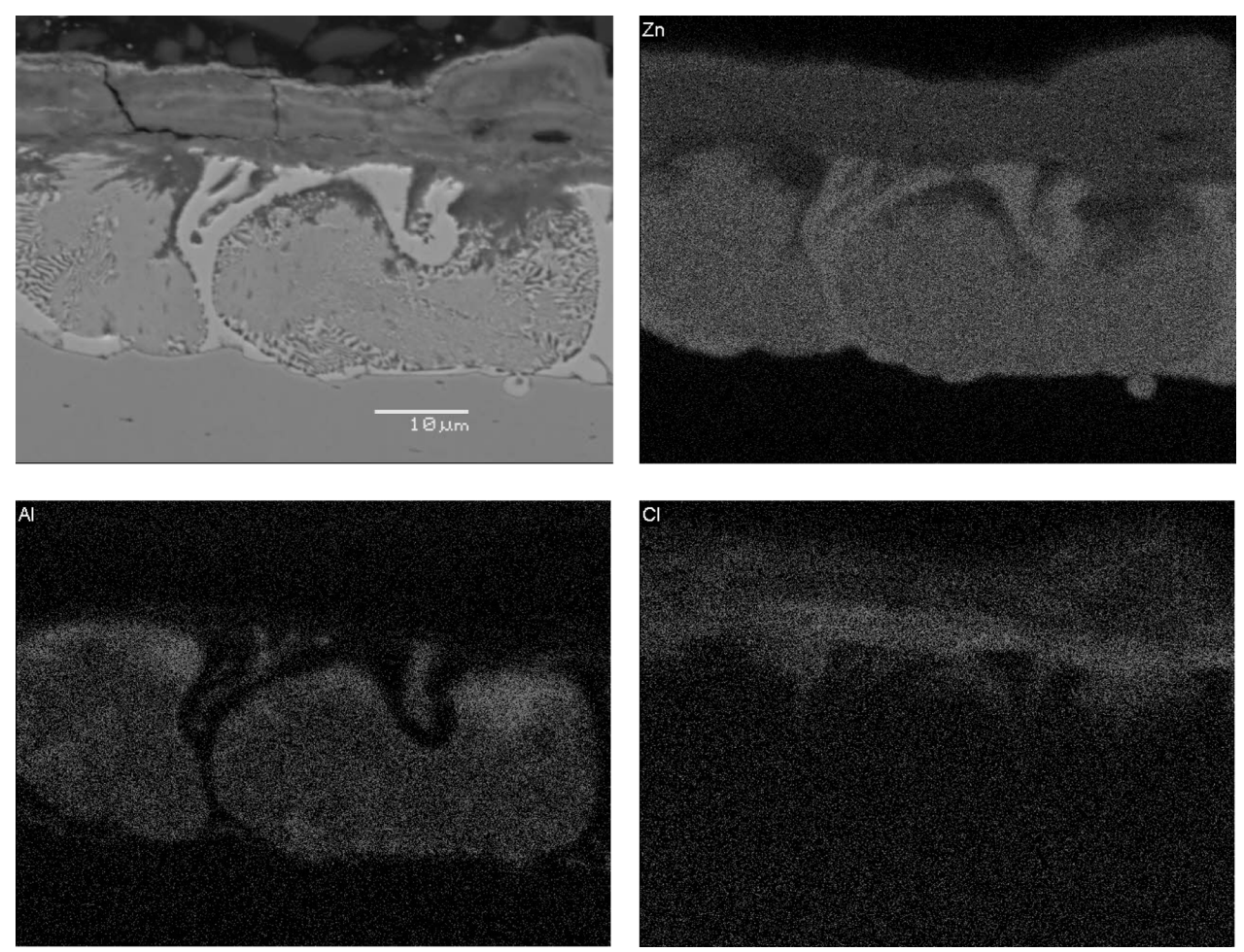

Fig. 6. Elemental mapping for a corroded $15 \mathrm{Al}$ coating. The corrosion product covering the coating surface is enriched in zinc and chlorine but was depleted in aluminum. The darker corroded areas within the primary $\alpha$-phase pockets in the normal image of the coating are associated with strong aluminum and chlorine signals and weak zinc signals. The chlorine was mostly enriched along the corrosion front.
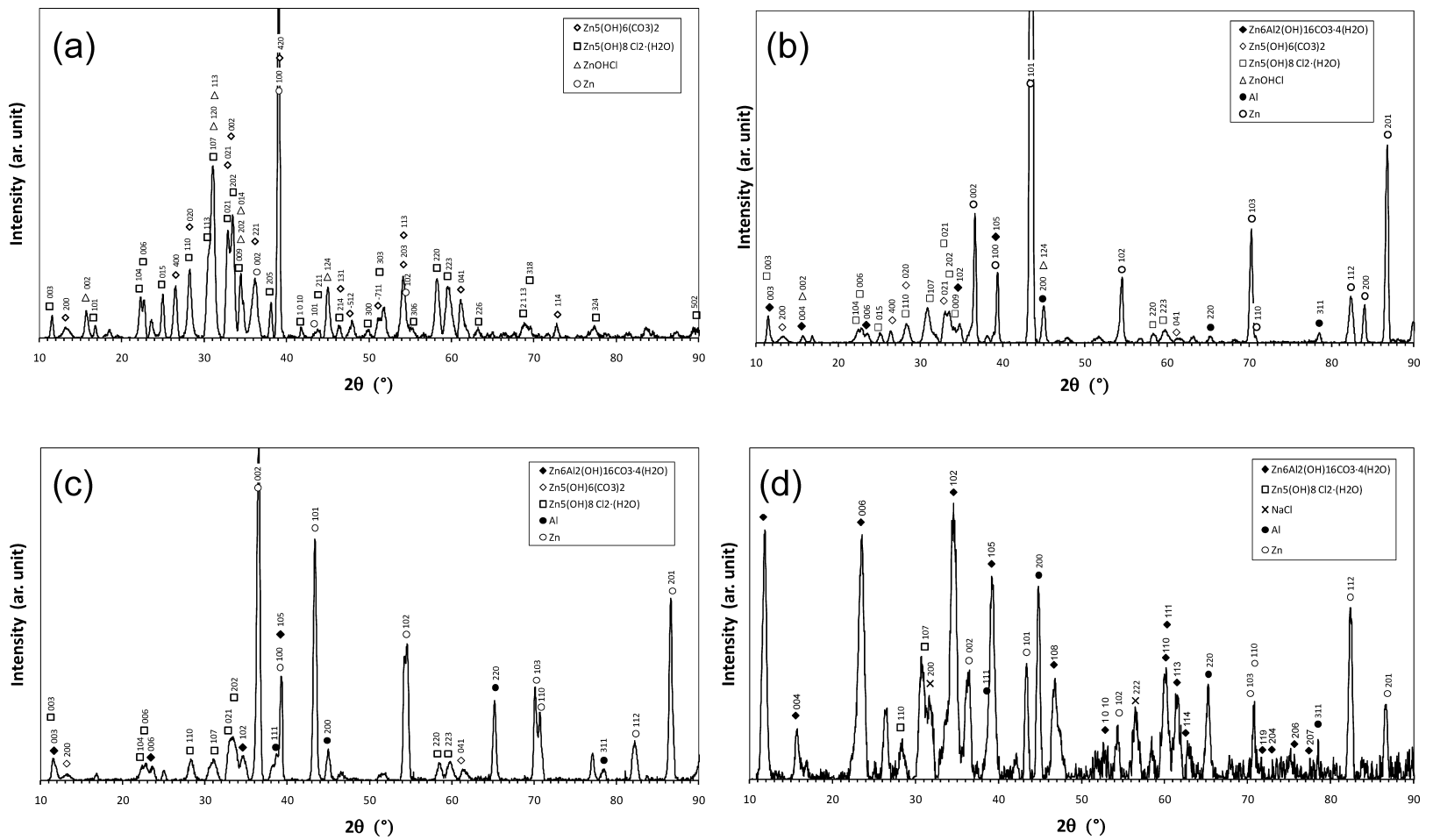

Fig. 7. X-ray diffraction patterns generated from (a) $\mathrm{HDG}$ coating containing $0.003 \% \mathrm{Al}$ (b) $5 \mathrm{Al}$, (c) $15 \mathrm{Al}$ and (d) $23 \mathrm{Al}$. The corrosion product on the $23 \mathrm{Al}$ coating was mainly the zinc aluminum carbonate hydroxide hydrate.

23Al coatings, respectively. Peak positions for all relevant corrosion compounds were calculated using their crystallographic data, and these calculated positions are identified and marked in the patterns. It was found that the actual positions of all major peaks situated within $0.2^{\circ}$ of their calculated $2 \theta$ values, except for $\mathrm{Zn}_{6} \mathrm{Al}_{2}(\mathrm{OH})_{16} \mathrm{CO}_{3} \cdot 4\left(\mathrm{H}_{2} \mathrm{O}\right)$ peaks for $23 \mathrm{Al}$ due to the isomorphic structure of $\mathrm{Zn}_{0.56} \mathrm{Al}_{0.44}(\mathrm{OH})_{2}\left(\mathrm{CO}_{3}\right)_{0.22} \cdot x\left(\mathrm{H}_{2} \mathrm{O}\right)$, as discussed earlier.

Following the positive identification of the corrosion products, further analyses of the mass losses and gains of all coatings were carried out. The data are tabulated in Table 1. The ratio of the gain to the loss was calculated. On 
Table 1. The mass gain/loss of various coatings after the first corrosion test.

\begin{tabular}{lccccccc}
\hline & HDG & GA & GF & $5 \mathrm{Al}$ & $15 \mathrm{Al}$ & $23 \mathrm{Al}$ & GL \\
\hline Gain $\left[\mathrm{g} / \mathrm{m}^{2}\right]$ & 54.8 & 24.0 & 24.0 & 27.2 & 21.0 & 45.3 & 14.4 \\
\hline Loss $\left[\mathrm{g} / \mathrm{m}^{2}\right]$ & 67.6 & 38.6 & 28.0 & 30.1 & 22.2 & 41.6 & 3.7 \\
\hline Ratio & 0.81 & 0.62 & 0.86 & 0.90 & 0.95 & 1.09 & 3.87 \\
\hline
\end{tabular}

Table 2. The related mass gain/loss ratio for various corrosion products.

\begin{tabular}{lc}
\hline Corrosion Product & Gain/Loss Ratio \\
\hline $\mathrm{Zn}_{5}(\mathrm{OH})_{6}(\mathrm{CO} 3)_{2}$ & 0.68 \\
\hline $\mathrm{Zn}_{5}(\mathrm{OH})_{8} \mathrm{Cl}_{2} \bullet\left(\mathrm{H}_{2} \mathrm{O}\right)$ & 0.69 \\
\hline $\mathrm{ZnOHCl}$ & 0.80 \\
\hline $\mathrm{Zn}_{6} \mathrm{Al}_{2}(\mathrm{OH})_{16} \mathrm{CO}_{3} \bullet 4\left(\mathrm{H}_{2} \mathrm{O}\right)$ & 0.91 \\
\hline $\mathrm{Zn}_{0.56} \mathrm{Al}_{0 \cdot 44}(\mathrm{OH})_{2}\left(\mathrm{CO}_{3}\right)_{0.22} \cdot \mathrm{x}\left(\mathrm{H}_{2} \mathrm{O}\right)$ & 1.16 \\
\hline
\end{tabular}

perusing the data, a trend is self-evident: the ratio increases with increasing aluminum content in the coating. The mass gain is largely attributable to the functional groups and the crystallized water in the corrosion products whereas the mass loss is directly related to the metallic components in the corrosion products. The corresponding stoichiometric mass gain/loss ratios for various corrosion products found on $\mathrm{HDG}, 5 \mathrm{Al}, 15 \mathrm{Al}$ and $23 \mathrm{Al}$ coatings in the first corrosion test are listed in Table 2 . It is obvious that the aluminumbearing corrosion products have higher gain/loss ratios mainly because the atomic weight of aluminum is much less than that of zinc. The higher the aluminum content in the corrosion product, the higher the gain/loss ratio becomes. The gain/loss ratios of the coatings listed in Table 1 are closely related to the ratios for corrosion products listed in Table 2. The mass gain/loss ratio for GL in Table 1 was skewed to a large value due to a very low mass loss and an additional mass gain by the pickup of $\mathrm{NaCl}$. The analysis of the change in the mass gain/loss ratio with coating aluminum provided supplemental evidence, in addition to the $\mathrm{XRD}$ results, of the evolution in corrosion products with increasing coating aluminum content.

\section{Discussion}

Aluminum additions to a galvanizing bath can enhance coating appearance and reduce zinc consumption by reducing the oxidation of the bath metal. Added in sufficient amounts, aluminum also affords the control of silicon reactivity $^{5)}$ and can greatly reduce the rate of dross generation in galvanizing or totally change the nature of the dross particles from $\mathrm{Zn}-\mathrm{Fe}$ compounds to iron aluminides. The former, being heavier than the molten zinc, sink to the bottom of the kettle while the latter is lighter than the molten $\mathrm{Zn}$ $\mathrm{Al}$ alloy and floats to the top of the bath, thereby facilitating its removal from the bath, provided that the aluminum content of the alloy is below $30 \%$.

The addition of aluminum to zinc-based alloys is known to improve the corrosion resistance of a coating. For exam- ple, coatings of $\mathrm{Zn}-5 \% \mathrm{Al}$ alloy containing misch metals have been shown to outlast HDG pure zinc coatings in various tests or services by a factor of about two ${ }^{6}$; a coating of $\mathrm{Zn}-55 \% \mathrm{Al}-1.5 \% \mathrm{Si}$ alloy has been proven to possess the best corrosion resistance among all zinc-based coatings. However, the corrosion resistance of a coating does not improve monotonically with the aluminum content of the coating in all environments. Atmospheric exposure of coatings containing aluminum levels from 0 to $70 \%$ suggested that only in severe marine environments does the aluminum addition improve the corrosion resistance of the coating based on the time elapsed to the first appearance of the red rust. $^{7)}$ In this comparative study, the corrosion resistance of the tested coatings peaked at 4 to $7 \% \mathrm{Al}^{7,8)}$ With a further increase in coating aluminum content, the corrosion resistance declined and a large increase in the coating durability occurred only when the coating aluminum content exceeded $40 \%{ }^{7)}$ Test results published by Humayun, ${ }^{8)}$ in which the corrosion resistance is measured by weight loss, support this observation. On the other hand, data generated in other long-term atmospheric exposures and in laboratory accelerated corrosion tests failed to substantiate these observations. These tests suggested that the aluminum addition improved the coating corrosion resistance in general, although the effect peaked at 4 to $7 \% \mathrm{Al}^{9}{ }^{9}$ In this study, the corrosion performance of $\mathrm{Zn}-\mathrm{Al}$ coatings peaked at $12 \%$ Al instead. Such a discrepancy is believed to stem from a number of factors: first, the coating sample production methods were quite different. Samples used in Townsend and Borzillo's ${ }^{7)}$ tests were produced on a pilot-scale continuous galvanizing line and coating thickness was controlled at 20 to $25 \mu \mathrm{m}$ using coating rolls. Such a wiping action could significantly alter the coating microstructure, thereby affecting corrosion performance as well. On the other hand, the thickness of the coating samples in this study was naturally achieved. No effort was exercised to achieve a certain coating thickness. Secondly, the types of corrosion tests were different. Townsend and Borzillo conducted a longterm atmospheric exposure test whereas the present authors conducted an accelerated laboratory test. The rating criterion of corrosion performance was also different. Townsend and Borzillo judged the coating performance by time period when the first red rust appeared. Consequently, coating thickness uniformity could significantly affect the test outcome. In the present study, the coating performance was judged by weight loss. Unfortunately, no analysis of coating microstructure was carried out by those authors, and the corrosion mechanism was not explored. As such, a meaningful discussion of the discrepancy would be difficult.

The corrosion performance of coatings could be affected by numerous factors, such as galvanizing parameters, coating surface treatment prior to test, sample handling, sample arrangements at the test site or in the environmental chamber, etc. As a result, a clear understanding of the corrosion mechanism is critical for the interpretation of these seemingly conflicting observations. Regrettably, a brief literature survey carried out by the present authors revealed that the corrosion data were frequently reported without any exploration of the related corrosion mechanisms. ${ }^{7,8)}$ On the other hand, detailed studies of corrosion mechanisms are frequently focused on one (5\%) or two (5\% and $55 \%)$ alu- 
minum compositions only, ${ }^{10)}$ and the researchers believed that the corrosion mechanisms discovered in the studies were universally applicable to all aluminum-containing coatings.

It is generally believed that the addition of aluminum to zinc will invariably improve the corrosion resistance of zinc coatings because pure aluminum possesses an extraordinary corrosion resistance. It is suggested that when $\mathrm{Zn}-\mathrm{Al}$ coatings are subjected to a corrosive environment, the zinc preferentially dissolves, leaving an aluminum-rich porous structure surviving in the coatings. ${ }^{11)}$ Because aluminum in this porous structure could be passivated and, hence, would be cathodic with respect to the steel substrate, red rust would occur. Indeed aluminum owes its excellent corrosion resistance to its ability to form an oxide film that is bonded strongly to its surface and that, if damaged, reforms immediately in most environments. The oxide film that develops in normal atmosphere is much thicker than $1 \mathrm{~nm}$ and is composed of two sublayers. The inner sublayer is a compact amorphous barrier layer. ${ }^{12)}$ Such a capability is preserved in $\mathrm{Zn}-55 \% \mathrm{Al}-1.5 \% \mathrm{Si}$ coatings, but not in zinc coatings containing aluminum less than $40 \%$. In these coatings, the aluminum-rich $\alpha$-phase could contain over $70 \% \mathrm{Zn}$. As such, it does not have the capability of forming the barrier oxide film when it coexists with the zinc-rich $\beta$-phase in corrosive environments. Also, when the coating solidifies, the aluminum-rich $\alpha$-phase forms a primary dendritic skeleton within the coating in the hypereutectic composition region $(>5 \% \mathrm{Al})$. The $\alpha$-phase is further decomposed through the eutectoid reaction into finely dispersed zinc-rich and aluminum-rich zones at ambient temperatures due to the high diffusivity of zinc at such temperatures. Regardless of which zones corroded first, a porous aluminum-rich structure would not likely exist. Indeed, experimental work and case studies carried out at the authors' laboratory failed to locate such a porous structure in corroded $\mathrm{Zn}-\mathrm{Al}$ coatings.

The standard electrode potential of pure aluminum is much more negative than that of pure zinc. As a result, when the two metals are electrochemically coupled, the aluminum will be the anode if it is not covered by a protective oxide film. In the present case, aluminum existed in the coatings as the solvent of the solid solution $\alpha$-phase. At an elevated temperature, the $\alpha$-phase could contain zinc in excess of $80 \%$ and yet maintain its face-centered cubic crystallographic structure. When fully decomposed through the eutectoid reaction, it could still contain over $1 \% \mathrm{Zn}$. The electrolytic solution potential of such a decomposed $\alpha$ phase is about $-1.06 \mathrm{~V}$ using a $0.1 \mathrm{~N}$ calomel electrode, ${ }^{13)}$ only slightly more anodic than that for zinc at $-1.01 \mathrm{~V}$. It is, therefore, expected than the $\alpha$-phase will corrode first and slightly faster than the $\beta-\mathrm{Zn}$ in decomposed primary $\alpha$ phase pockets.

Due to the fast solidification process in coatings containing aluminum in excess of $5 \%$, a dendritic frame of aluminum-rich $\alpha$-phase coexists with a degenerated eutectic frequently consisting of $\beta$-Zn only. The $\beta$-Zn envelops the dendritic $\alpha$-phase which appears as pockets in a cross-section, as shown in Fig. 4. The volume fraction of the primary $\alpha$-phase in the coating is a function of the coating aluminum content and the cooling rate to a lesser degree. If a coating containing aluminum over $18 \%$ is cooled down at

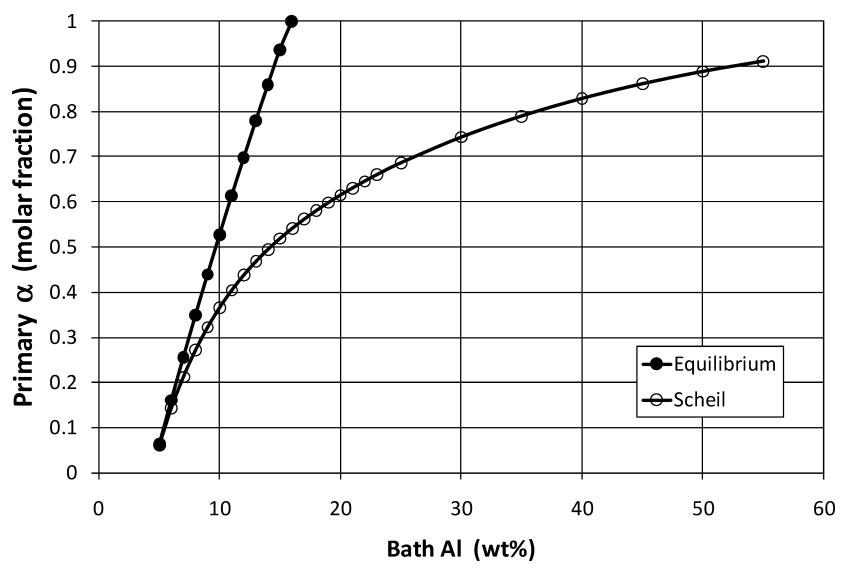

Fig. 8. Volume fractions of the primary $\alpha$-phase in a coating as a function of the aluminum content of the coating alloy. Solid dots are associated with an equilibrium solidification process whereas open circles are associated with Scheil's assumption of no solid-state diffusion during a fast solidification process. ${ }^{14)}$

an extremely low rate and obtains an equilibrium microstructure, the coating will consist entirely of the primary $\alpha$ phase. However, commercial coatings can never obtain an equilibrium microstructure due to the relatively high cooling rate achieved in a production environment. Calculations based on Scheil's ${ }^{14)}$ assumption suggest that there will still be over $10 \%$ (molar fraction) of eutectic in a coating containing $50 \% \mathrm{Al}$, as shown in Fig. 8. Due to the relatively low melting point of zinc, its diffusivity is significant when a coating solidifies. In a $\mathrm{Zn}-\mathrm{Al}$ coating, the eutectic is always degenerated whereby the residual aluminum in the solidifying liquid attaches to the exiting primary $\alpha$ dendrite arms and the zinc forms separate grains nearby. These zinc grains appear to possess a much better corrosion resistance than the aluminum-rich $\alpha$ pockets. No fundamental study on this phenomenon is known to the present authors. However, it is well known that the corrosion performance of zinc can be significantly affected by the iron content in the zinc. $^{15,16)}$ Teel and Anderson ${ }^{16)}$ found that a zinc anode functioned well only when the iron content was maintained at a very low level in the high purity zinc anodes. They recommended that the iron content be kept below $0.0015 \%$ in otherwise pure zinc. It is also known that the iron content in zinc powder for alkaline cells is kept at below 5 ppm because iron possesses a low hydrogen overvoltage. ${ }^{17)}$ The iron solubility in liquid zinc is about $0.03 \%$ at the galvanizing temperature of $450{ }^{\circ} \mathrm{C}$. Excess iron will be largely entrapped in the coating as it solidifies and will subsequently precipitate out as tiny particles. These particles will act as cathodes in corrosion galvanic cells, thereby adversely affecting the corrosion resistance of the coating. In a zinc bath containing a high aluminum level, the iron dissolved in the liquid alloy is almost completely scavenged by aluminum through the formation of iron aluminides during coating solidification. When the aluminum level in a coating alloy exceeds $4 \%$, the iron solubility in the molten alloy is below $1 \mathrm{ppm}$. Iron entrapped in the degenerated eutectic $\beta$ - $\mathrm{Zn}$ in coatings is even lower in concentration. This could be a contributing factor to the better corrosion resistance of $\beta-\mathrm{Zn}$. To verify this suggestion, the microstructure of a cor- 


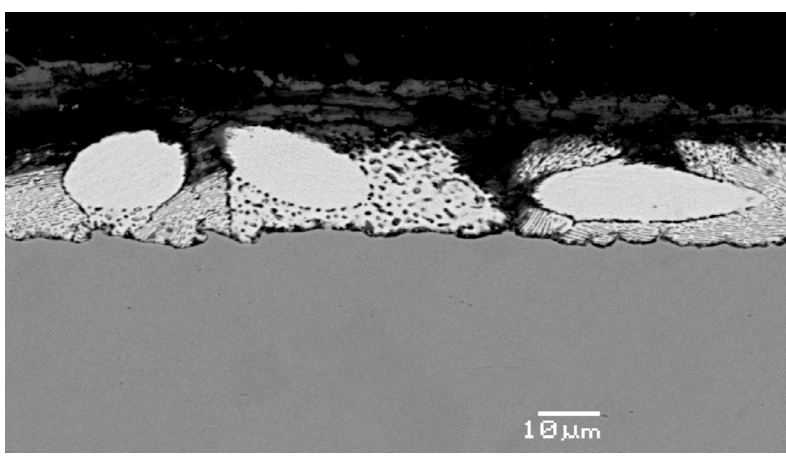

Fig. 9. Cross-sectional view of the corroded grain structure of a $\mathrm{Zn}-5 \% \mathrm{Al}$ with misch metals sample. The primary $\beta$ - Zn grains (white ovals) evidently possessed better corrosion resistance than the eutectic colonies.

roded $\mathrm{Zn}-5 \% \mathrm{Al}$ coating sample was examined: a representative micrograph of the corroded grain structure is shown in Fig. 9. It can be seen that the primary $\beta$-Zn grains possessed better corrosion resistance than the eutectic colonies. This finding supports the suggestion that the corrosion resistance of zinc was much improved when the iron solubility of the alloy dropped to below $1 \mathrm{ppm}$. Consequently, the coating corrosion performance will generally improve with an increase in the aluminum content in the coating until the volume fraction of the degenerated eutectic $\beta$-Zn in the coating is reduced to an insignificant amount.

The existence of a critical volume fraction of the degenerated eutectic in $\mathrm{Zn}-\mathrm{Al}$ alloy coatings is likely an important factor affecting its corrosion performance because the morphology of the $\beta$ - $\mathrm{Zn}$ could be a contributing factor to the corrosion resistance of the coatings. If the dendritic $\alpha$ frame in the coating is totally enveloped by the degenerated eutectic $\beta-\mathrm{Zn}$, the corrosion resistance of the coating can be further improved. This metallurgical variable is probably one of the main reasons why the corrosion resistance of coatings peaked at about $12 \% \mathrm{Al}$. The microstructure of a coating can be easily affected by a number of factors, and corrosion performance of a coating can also be influenced by numerous factors. As a result, the aluminum content of the coating which exhibited the best corrosion resistance in a test could vary around $12 \% \mathrm{Al}$. In this test, the $12 \mathrm{Al}$ coating performed the best. However, the difference in corrosion performance of $9 \mathrm{Al}, 12 \mathrm{Al}$ and $15 \mathrm{Al}$ coatings was marginal.

Corrosion products change with the aluminum content in the coatings. This signals an evolution of the corrosion mechanism. The corrosion products consist mainly of the simonkolleite $\mathrm{Zn}_{5}(\mathrm{OH})_{8} \mathrm{Cl}_{2} \cdot \mathrm{H}_{2} \mathrm{O}$, the hydrozincite $\mathrm{Zn}_{5}$ $(\mathrm{OH})_{6}\left(\mathrm{CO}_{3}\right)_{2}$, and the zinc aluminum carbonate hydroxide hydrate $\mathrm{Zn}_{6} \mathrm{Al}_{2}(\mathrm{OH})_{16} \mathrm{CO}_{3} \cdot 4\left(\mathrm{H}_{2} \mathrm{O}\right)$. The $\mathrm{Zn}_{6} \mathrm{Al}_{2}(\mathrm{OH})_{16} \mathrm{CO}_{3}$. $4\left(\mathrm{H}_{2} \mathrm{O}\right)$ content of the corrosion product increased with an increase in the aluminum content in the coatings; it became the dominant corrosion product for the $23 \mathrm{Al}$ coating. This finding is consistent with the observations of Nishihara et $a l{ }^{10)}$ By means of photoemission spectroscopy using synchrotron radiation and $\mu$-FT-IR spectroscopy, these researchers elegantly demonstrated that aluminum in zinc coatings retards the formation of hydrozincite. They also found that the nature of the corrosion products forming in an early stage of the corrosion test are similar on $\mathrm{Zn}-5 \% \mathrm{Al}$ and $\mathrm{Zn}-55 \% \mathrm{Al}$ coatings. Based on the above observations, these researchers attributed the improvement in corrosion resistance of these two types of coatings to the fact that the corrosion products on the coatings are insulators which restrained the reduction of oxygen, thereby retarding the anodic dissolution. However, the corrosion performances of $\mathrm{Zn}-5 \% \mathrm{Al}$ and $\mathrm{Zn}-55 \% \mathrm{Al}$ coatings were quite different in industrial applications and in laboratory tests. Furthermore, the dominance of $\mathrm{Zn}_{6} \mathrm{Al}_{2}(\mathrm{OH})_{16} \mathrm{CO}_{3} \cdot 4\left(\mathrm{H}_{2} \mathrm{O}\right)$ in the corrosion product accompanied a decline in the coating corrosion resistance in the present study. As such, the improvement in corrosion performance brought about by the addition of aluminum through the above mechanism is probably limited. If this mechanism dominates, corrosion performance of the $\mathrm{Zn}-\mathrm{Al}$ coating would monotonically improve with an increase in the coating aluminum content. However, the results obtained in the present study indicate that the corrosion resistance of $\mathrm{Zn}-\mathrm{Al}$ coatings decreased when the aluminum content reached $23 \%$. Atmospheric exposure of aluminum-containing zinc coatings also suggests the existence of a minimum in corrosion resistance at an aluminum content of about $35 \%$. $^{7)}$ As mentioned earlier, coatings containing aluminum in excess of $45 \%$ regain the capability of forming a protective alumina film on their surfaces, thereby ushering in a new corrosion protection mechanism for this type of coating.

\section{Conclusions}

The corrosion performance of zinc coatings containing aluminum up to $23 \%$ was assessed in modified salt-spray tests. The highest corrosion resistance was exhibited by coatings containing about $12 \% \mathrm{Al}$. The corrosion products consisted mainly of simonkolleite $\mathrm{Zn}_{5}(\mathrm{OH})_{8} \mathrm{Cl}_{2} \cdot \mathrm{H}_{2} \mathrm{O}$, hydrozincite $\mathrm{Zn}_{5}(\mathrm{OH})_{6}\left(\mathrm{CO}_{3}\right)_{2}$, and zinc aluminum carbonate hydroxide hydrate $\mathrm{Zn}_{6} \mathrm{Al}_{2}(\mathrm{OH})_{16} \mathrm{CO}_{3} \cdot 4\left(\mathrm{H}_{2} \mathrm{O}\right)$. The $\mathrm{Zn}_{6} \mathrm{Al}_{2}$ $(\mathrm{OH})_{16} \mathrm{CO}_{3} \cdot 4\left(\mathrm{H}_{2} \mathrm{O}\right)$ content of the corrosion product increased with an increase in aluminum content in the coatings. It is the dominant corrosion product for the $23 \mathrm{Al}$ coating. SEM-EDX analyses revealed that the microstructural features formed by the primary aluminum-rich $\alpha$-phase frequently corroded first and faster than the zinc-rich $\beta$-phase in these coatings. However, the corrosion mode of these coatings is generally uniform corrosion, i.e., the corrosion front advanced more or less uniformly along the coating thickness. It appears that the corrosion resistance of the zinc component in the coatings increases with an increase in the aluminum content of the coatings. The $\beta$-phase of the degenerated eutectic possesses a much better corrosion resistance than other microstructural features in the coatings. A microstructure consisting of the primary $\alpha$ dendrite enveloped by the $\beta$-phase is better than an all eutectic microstructure, making the corrosion resistance of 7Al, 9Al, $12 \mathrm{Al}$ and $15 \mathrm{Al}$ better than that of $5 \mathrm{Al}$.

In summary, the volume fraction and the morphology of the degenerated eutectic $\beta$-phase are the two main contributors to the existence of a maximum corrosion resistance for zinc coatings containing approximately $12 \mathrm{Al}$.

\section{Acknowledgements}

The corrosion tests, including the procurement and 
preparation of the coating samples, data collection and metallurgical section preparation were carried out by Steve Murray, Fred Coady, Neil Gao and Daniel Jochim. The authors would like to express their thanks to Fred Coady for constructive discussions of corrosion mechanisms. The authors also thank Teck for allowing the publication of the test results and acknowledge the assistance of Angeline M. Prskalo in the manuscript preparation.

\section{REFERENCES}

1) M. Ranjan, E. Klerks and W. J. van Ooij: Proc. of Intergalva'03, Amsterdam, Session: Sustaining Product Development (3), European General Galvanizers Association, Surrey, United Kingdom, (2003).

2) W. J. van Ooij, M. Ranjan, A. Joshi, J. Verstappen, J. Zervoudis and G. W. Poag: Proc. of Intergalva'06, Naples, Italy, Session: The Metallurgy of Galvanizing (2). European General Galvanizers Association, Surrey, United Kingdom, (2006).

3) X. G. Zhang, J. Hwang and W. K. Wu: Proc. of Galvatech'98, Ed. by N. Masuko, ISIJ, Tokyo, Japan, (1998), 410.

4) N. Larche and T. Prosek: Contract Research Report IC 89465, French Corrosion Institute, 220 rue Pierre Rivoalon, 29200 Brest,
France, (2008), 1.

5) N.-Y. Tang: J. Phase Equilib. Diffus., 29 (2008), 333.

6) J. L. Hostetler: Corrosion Resistance of Unpainted Zn-5\%Al with Misch Metals Steel, ILZRO Publication, Research Triangle Park, NC, USA, (1992).

7) H. E. Townsend and A. R. Borzillo: Proc. of Galvatech'95, The Use and Manufacture of Zinc and Zinc Alloy Coated Sheel Steel Product into the 21st Century, AISI, Chicago, IL, USA, (1995), 171.

8) A. Humayun: Proc. of National Conf. on Coated Steel Technol., Applications \& Markets, New Delhi, India, (1994), 22.

9) A. Hannick: Proc. of Intergalva'79, Paris, France, (1979), 42.

10) K. Nishihara et al.: Proc. of Galvatech'07, ISIJ, Tokyo, Japan, (2007), 665.

11) ASM Handbook, Vol. 13B, Corrosion: Materials, (2005), 406.

12) ASM Handbook, Vol. 13B, Corrosion: Materials, (2005), 95.

13) R. H. Brown, W. L. Fink and M. S. Hunter: Trans. AIME, 143 (1941), 115.

14) E. Scheil: Z. Metallkd., 34 (1942), 70

15) F. C. Porter: Corrosion Resistance of Zinc and Zinc Alloys, Marcel Dekker Inc., New York, (1994), 334.

16) R. B. Teel and D. B. Anderson: Corrosion, 12 (1956), 343

17) F. C. Porter: Zinc Handbook, Marcel Dekker Inc., New York, (1991), 418. 